\title{
APPLICABILITY OF RISKY DECISION-MAKING THEORY TO UNDERSTAND DRIVERS' BEHAVIOUR DURING TRANSITIONS OF CONTROL IN VEHICLE AUTOMATION
}

\section{APLICABILIDADE DE MODELOS DE TOMADA DE DECISÃO DE RISCO PARA ENTENDER O COMPORTAMENTO DE MOTRISTAS DURANTE RETOMADAS DE CONTROLE EM AUTOMAÇÃO VEICULAR}

\author{
Rafael Cirino Gonçalves ${ }^{1}$, M.Sc. \\ Tyron L. Louw ${ }^{1}$, PhD. \\ Gustav Markkula ${ }^{1}, \mathrm{PhD}$. \\ Natasha Merat ${ }^{1}$, Prof.
}
(1) University of Leeds | Institute for Transport Studies (ITS)
tsrg@leeds.ac.uk
(2) University of Leeds | Institute for Transport Studies (ITS)
t.l.louw@leeds.ac.uk
(3) University of Leeds | Institute for Transport Studies (ITS)
g.markkula@leeds.ac.uk
(4) University of Leeds $\mid$ Institute for Transport Studies (ITS)
n.merat@leeds.ac.uk

Decision-making, Behavioural modeling, Automated vehicles.

This work presents a consideration of the applicability of risky decision-making theory models as a tool to understand drivers' take-over behaviour from vehicle automation, while also incorporating the "Out of the Loop" concept and the process of Situation Awareness Recovery. A methodological discussion is provided, and implications for the processes involved in system design developments are presented. Finally, the paper concludes that the process of evidence accumulation in risky decision-making theory models has strong parallels with the process of Situation Awareness recovery. We argue that evidence accumulation models can be used as a tool to understand what information is used by drivers for achieving safe transitions of control from automation so that this knowledge can be used for a better, and more human-centred design of future in-vehicle interfaces. In the end, this paper presents one theoretical model as a practical implementation of the theory discussed in experimental datasets.

Tomada de decisão, Modelagem comportamental, Automação veicular.

Este trabalho apresenta uma apreciação teórica da aplicabilidade de modelos de tomada de decisão de risco como uma ferramenta para entender o comportamento de motoristas durante retomadas de controle de um veículo automatizado. O artigo se foca na relação entre o conceito de "Out of the Loop" e consciência da situação. Uma discussão metodológica é feita, e suas implicaçóes para o design de produtos é apresentada. Ao fim da discussão, este artigo conclui que o processo de acumulação de evidência em modelos de tomada de decisão possui paralelos fortes com o conceito de retomada de consciência da situação. Dito isto, modelos de acumulação de evidência podem ser tuilizados como ferramentas para entender como motoristas usam a informação para tomar decisões seguras, e esta informação pode ser reforçada no design de interfaces embarcadas. Ao fim do artigo, um modelo conceitual é apresentado como sugestão para aplicação prática da teoria proposta em dados experimentais.

\section{Introduction}

Among the human factors-related challenges of implementing vehicle automation, is ensuring safe responses from users during transitions of control. Recent research into this issue forms part of a larger body of research regarding the better design of human-machine interfaces, spanning multiple domains and decades. These challenges highlight an old irony of automation, where the more reliable the automation, the less prepared the human is to react in a time of need (Bainbridge, 1985). This is 
especially true for higher levels of vehicle automation, which do not require continuous monitoring of the driving task, but still rely on users to resume control, for example, when a system limitation is reached (Level 3. See SAE, 2018 for a complete description of the levels of vehicular automation).

Many recent driving simulator studies, for example, those described by Louw \& Merat (2017), have identified that drivers in higher levels of vehicle automation (SAE L2+) are removed from the decision-making and control loops of the driving task, placing them "out of the loop" (see Merat et al. (2018) for a recent description of the term). This disengagement from the loops is thought to reduce drivers' capacity to react in dangerous situations, increasing the likelihood of collisions.

Many researchers have tried to understand what constitutes a safe transition of control from automation, investigating what factors influence the success of a transition. For example, Gold et al. (2013) demonstrated that drivers' response to an impending collision, following a request for a transition of control, is dependent on the amount of time given to drivers for this response. These authors report that when drivers were given less time to react, they reacted faster, but more erratically, as shown by the vehicle's lateral and longitudinal accelerations. In contrast, when given more time to respond to an impending collision, drivers reacted more slowly but had a more stable response profile.

Zeeb at al. $(2015,2016)$ have shown that drivers' take-over time and the quality of this take over (measured as vehicle lateral deviation), is linked to their attention to the road environment during automated driving, with higher levels of distraction to other, non-driving-related tasks, leading to a deterioration of take-over quality. However, Louw et al. (2018) suggest that take-over time and vehicle controllability alone are not good predictors of a safe transition of control, but rather the early mitigation of a threat, with earlier transitions of control leading to fewer collisions.

A common limitation of studies attempting to correlate drivers' visual attention with their performance on non-driving-related tasks during automation, is that most investigate the location of drivers' gaze, rather than attempting to understand how visual information, acquired from different sources during automation engagement, affects drivers' resumption of control. While there have been efforts to model the factors that influence drivers' capabilities to take-over control, and how they use the physical and mental resources they need to perform such an action, most have not managed to generate a predictive model, based on gaze patterns during take-overs (Happee et al., 2018). For example, in Victor et al. (2018), while have reported that some drivers, even though looking to the road centre, still failed to avoid crashes during a transition of control (similar to results also reported by Louw et al., 2017).

Studies in other domains have considered how visual information sampling affects decision making in humans (see Orquin \& Loose, 2013 for a complete literature review of these studies). For instance, Fiedler \& Glöckner (2012), identified that gamblers shift their gaze towards the gamble they are willing to make, before their decision, and used this information as a predictor of their choice selection.

This paper proposes that the application of decision making theories, and related models, can be used to address some of the gaps in research on user resumption of control from vehicle automation, by providing a quantifiable method of linking the acquisition of specific information from the environment to the probability of a particular response (Orquin \& Loose, 2013). Currently, there are only a few studies that highlight the possibility of such a link (c.f. Markkula et al., 2018). In this work, we consider how theoretical models for risky decision-making can be used to study drivers' transition of control in automation by observing their visual sampling behaviour during different stages of the take over process.

We begin with outlining the two theoretical bases of this work: decision-making theory, and the human factors of transitions of control. Thereafter, the two theories will be compared, especially regarding their analogous processes of Situation Awareness acquisition and evidence accumulation. Finally, this paper considers how such an approach can generate outputs that may be applied by presenting a conceptual mathematical model that can be used to fit experimental data regarding transitions of control to understand human behaviour.

\section{Transitions of control from vehicle automation}


This section of the paper aims to define key concepts in the field of human factors of transitions of control, such as the decision-action loop, Situation Awareness, and the issues that are related to this process. With a clear definition of this concept in hand, it will be possible to compare them to the concepts related to the decision-making theory, understanding how they might interact and complement each other.

The term transition of control was described by Louw (2017) as: "the process and period of transferring responsibility of, and control over, some or all aspects of a driving task, between a human driver and an automated driving system." SAE (2018) complement this definition with a taxonomy, by outlining how a driver's responsibility varies across the different levels of automation, and a distinction if they were system- or driver-initiated transitions. The need for such transitions of control is partly based on current system limitations, in terms of the technology's operational design domain (see NHTSA, 2016, for a more descriptive definition of the problem), where vehicles cannot operate in all scenarios, and the human drivers are expected to supervise the automation and resume control, whenever a system limitation is reached. However, the inherent problem with such supervisory roles is diminished driving capabilities associated with the relinquishing of control, which his associated with several challenges when drivers are requested to resume control, especially in timecritical scenarios (Louw, 2017). Some of these issues are discussed below.

\subsection{The decision-dction loop}

According to many authors (e.g. Young, 2012), manual driving is a task which requires the driver to always be in the information processing "loop", with regards to their interactions with the surrounding road environment, as well as their ability to control and coordinate vehicle manoeuvres, involving steering, acceleration and braking. Thomas (2001) states that the operation of a vehicle is closely associated with constant feedback and feed-forward cycle of human interaction with the task. Here, humans' decisions and actions affect the situation, and this change is perceived once more by the individuals, who orient and adjust their behaviour accordingly. Merat et al. (2018) further complement this logic for the context of vehicle automation (based on the model purposed by Michon, 1985), by stating that there are two distinct loops in manual driving, which can be affected by ceding control to automation: one for motor-control coordination, and another for the several decision-making processes that need to be performed while driving. They suggest " (...) that "being in the loop" can be understood in terms of (1) the driver's physical control of the vehicle, and (2) monitoring the current driving situation (...)" (Merat et al., 2018). It must be noted that both loops continually interact with each other, and drivers must be aware of both their visual-motor coordination (see Wilkie et al., 2008 for a more descriptive definition of the term) and the surrounding environment, to safely maintain control of the task

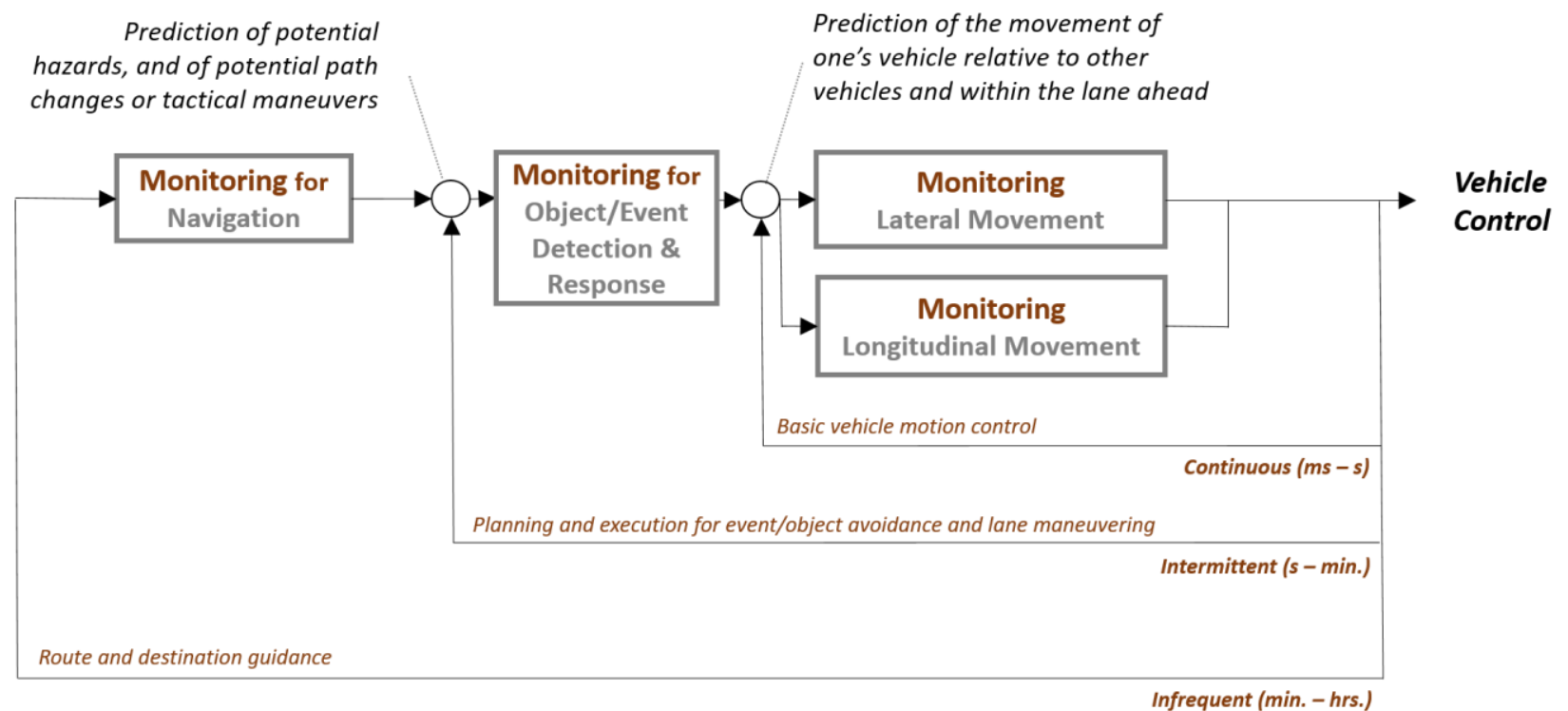

Figure 1. Representation of the decision-action loop and drivers' monitoring role in manual control of the driving task (Merat et al., 2019; based on Michon's model, 1985; Copyright (C) 2019 Springer. Reprinted with Permission of Springer Publications). 


\subsection{Situation awareness recovery}

Using driving simulator experiments, Louw et al. (2016), supplemented by previous evidence from Damböck et al. (2013), argue that by removing drivers from the decision-making and control loops, vehicle automation reduces drivers' Situation Awareness (SA; Endsley, 1995), which needs to be re-acquired in order to safely resume control and avoid potentially dangerous situations on the road
(Damböck et al., 2013). The definition of Situation Awareness used in this research, and defined initially by Endsley (1988), is: "the perception of the elements in the environment within a volume of time and space, the comprehension of their meaning, and the projection of their status in the near future." In short, SA can be divided into three levels (perception; comprehension and prediction), which allow humans to orient their decisions in a particular context and volume of time (Fig. 2).

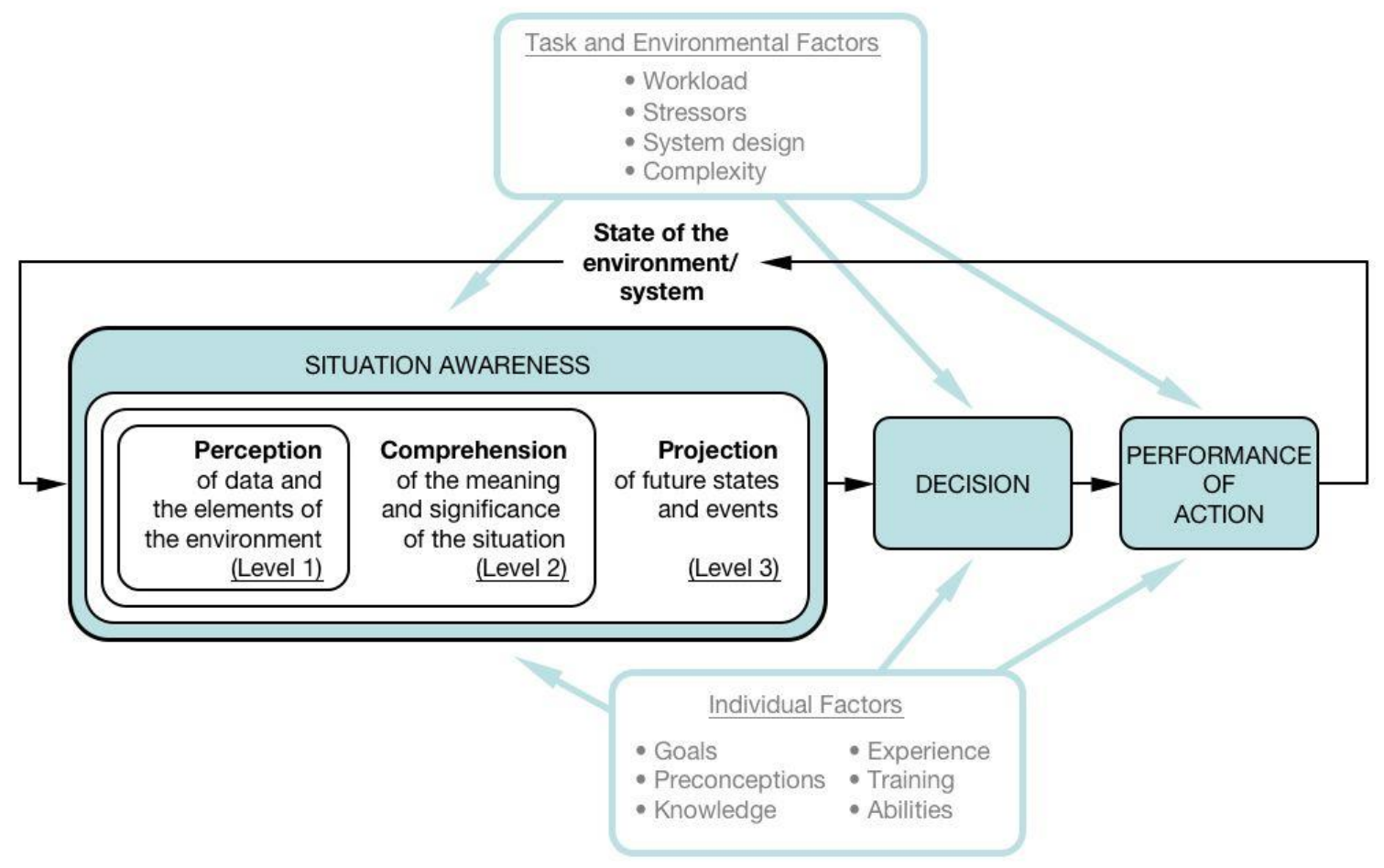

Figure 2. Endsley's model of SA. This is a synthesis of versions she has given in several sources, notably Endsley (1995) and Endsley et al. (2000), in Wickens (2008).

The loss of Situation Awareness and its relation to being "out of the loop" have been declared by a number of studies on vehicle automation (Carsten et al., 2012; Ohn-Bar \& Trivedi, 2016; Morando et al., 2019), some of which have considered how these concepts are affected by drivers' engagement in non-driving-related tasks. It is argued that upon a request to resume control from automation, drivers have to move their visual attention from the NDRT, to focus on other sources of information, related to the driving task, to acquire enough SA to take back control of the vehicle. Gartenberg et al. (2014) refer to this process (which is not only relevant to vehicle automation) as Situation Awareness Recovery or SAR. This is described as a visual scanning process with a considerable number of short fixations in different areas, with a significant lag of resumption in tasks, and a high probability of re-fixation to the same information source, more than once. Examples

of such a process was observed in Louw et al. (2019), who reported in their driving simulator experiments that drivers who were engaged in a visual non-driving-related task during automation (assumed to induce an OotL state) had a more scattered gaze pattern after resumption of control from a silent automation failure, compared to those who were required to monitor the road environment during automation.

One of the challenges for the human factors community in addressing this problem is that the process of SAR is accompanied by several barriers, called SA challenges (Endsley, 2006). Endsley \& Kriss (1995) named several challenges for the 
Situation Awareness acquisition, such as attention tunnelling, change blindness, stress on operators' (drivers') working memory, as well as the division of the information required from multiple sources, making it difficult for operators to gather all the information they might need in a reasonable amount of time (e.g. see Parasuraman \& Riley, 1998). For driving automation, it has been demonstrated that time pressure, or information overload, might affect the quality of drivers' performance. This is thought to be because drivers' attentional resources are continuously stretched by the high demands of the driving task itself, which is aggravated by automation (Goodrich \& Boer, 2003). The dispersion of drivers' gaze also competes between focused attention to the vehicle's heading (due to a visual-motor coordination, Wilkie et al., 2008) and hazard perception routines, which are generally characterised by an increased lateral gaze dispersion (Crundall et al., 1999). Therefore, drivers not only have to acquire information about the situation in the environment, and the current status of the system (an issue also reported by Endsley, 2006), but also have to recover their visual-motor coordination, which is degraded once you relinquish control from the vehicle (Mole et al., 2019). Many empirical studies show that this need to disperse visual attention to different sources affects drivers' performance, increasing risk of crashes (see Russel et al., 2016; Zeeb et al., 2015; Blommer et al., 2016; Louw et al., 2017; Merat et al., 2014; Gold et al., 2013; Damböck et al., 2013).

\section{Decision-making theory principles and models}

The definition of decision-making adopted in this work was proposed by Edwards (1954), and is defined as follows: "(...)given two states, A and B, into either one of which an individual may put himself, the individual chooses $\mathrm{A}$ in preference to $\mathrm{B}$ (or vice versa)". This definition was further developed by Simon (1959), who added organised this process into four main stages: 1) definition of the problem, 2) identification of possible solutions, 3) objective assessment of the value of each solution for the problem, 4) choice of the best solution. As human beings, we are continuously making decisions, based on our internal representation of what we should do in every situation, given certain parameters (stage 3 ). In a driving task, many actions involve a decision-making process. Some examples include deciding: a comfortable car-following distance (Boer, 1999), what gaps we will accept when changing lanes (Gipps, 1986), how we respond to a potential forward collision (Blommer et al., 2017), and whether to disengage from automation (see Markkula et al., 2018, for more examples).

In the context of this paper, decision-making can be defined as the drivers' choice to take-over control of the vehicle or not, and their take-over modality (how do they take-over). When constructing a model for such decision-making, to account for a good or bad decision, in terms of safety, we have as observable output variables the decision-making time (how long drivers took to decide to take-over), decision choice (how they reacted to the given scenario) and outcome (based on the objectives established for the given situation, were they able to achieve this goal?). Yet, there are several kinds of decision-making theory models, which may account for different aspects of human behaviour, and might be useful for certain situations and not others. Edwards (1954) also divided the decision-making theory models into two main spectrums, which their most recent and developed definitions shall be further explained in the later sections of this paper: the rational and risky decision-making models.

\subsection{Rational decision-making models}

The concept of rational decision-making (see Simon (1979) and March (1978) for a more descriptive definition of the term) is based on a metaphorical "thinking man", as a decision-maker. According to Simon (1979) and March (1978), a thinking man can be characterized as an individual by two main conditions: 1) as being capable of acquiring and distinguishing all possible relevant information for the decision in hand; and 2) the thinking man is capable of assigning the correct value of a specific choice, based on their established goal in each decision-making scenario. Based on these assumptions, two individuals would always arrive at the same conclusion, when making a rational decision about the same problem. The only difference between their choices would be personal bias, or what outcome they want from the decision.

Good examples of rational decision-making models can be seen in game theory (Nash, 1950), which posits that all choices made by an individual have a counterpart by a "hostile" opponent (like a chess game). The opponent will focus their actions on maximising their chances of achieving their goal, which is the opposite of the individual's goal. 
Another example of a rational decision can be seen in the utilitarianism theory, created by Jeremy Bentham and John Stuart Mill in the early 19th century. This theory holds that there are "greater goods" in life, and every moral action can be quantified in terms the outcome of "happiness", and that it is always right to maximise happiness in our choices in life for a "greater good" (for a more complete description of the term, see Mill, 1868). Indeed, rational decision-making processes are utopic in most cases, and their scope for applicability is limited, as everything needs to be quantifiable, such as in mathematical logic problem solutions (for examples, see Bell et al., 1988).

\subsection{Risky decision-making models}

According to decision-making theory, whenever the decision-maker is forced to make a decision without a clear notion of the possible outcomes of their choice, this process is considered to be a risky decision (Edwards, 1954). Models in the risky decision-making theory are based on the assumptions: 1) that not all variables can be accurately, or even wholly, quantified, 2) that humans are not certain about how their actions will affect the environment of the task in hand, and, 3) humans are not aware of are all the variables that they should consider to make their decision. Humans in that situation can estimate, based on their mental models (see Nielsen, 2010 for a description of the term), the probable outcomes for a given task for each possible action that they can perform, and use that information to guide their decision-making. In situations where the outcome of an individual's decision is not predictable, they need to account for a level of uncertainty as part of their decision-making process. Uncertainty is defined by Shaw (1983) as the inability of the decision-making to assign the correct value of an option, nor predict the outcomes of their decision to the given environment. This uncertainty concept is a key assumption underlying risky decision-making models and is discussed later in this paper. As humans' mental processing is not directly observable, risky decision-making models can be used to explain human behaviour based on certain assumptions. The most relevant ones are described below:

Evidence accumulation models assume that every decision-maker a priori does not have sufficient information about the situation to make a decision and will seek evidence that will influence their decision towards one of the outcomes known to them. Furthermore, every individual has a personal threshold of accumulated evidence that once reached, causes them to opt for one possible choice, over another (Ratcliff \& Smith, 2004). This threshold varied based on a number of factors, including experience, gender, personal attitudes and many others. It must be noted that the rate of evidence, or "drift", is accumulated differently for every person, which is also influenced by a number of factors. In the field of vehicle automation, Markkula et al. (2018) have demonstrated how to apply decision-making models based on evidenceaccumulation to explain, for example, what information drivers use to decide how to resume control from vehicle automation to avoid an incoming forward collision.

Bounded rationality models, first defined by Simon (1972), which holds that humans can make decisions based on the information available to them. These have similar assumptions to rational decision-making models but differ in that they assume that humans are not capable of considering all the relevant information to make a decision. This can be caused by a lack of cognitive resources, time pressure, or simple lack of knowledge about the presence of a particular source of information. Considering this paradigm, bounded rationality models assume that the decision-maker prioritises certain information over others (randomly or selectively). This prioritised information will most likely bias the decision towards a particular choice, depending on the information sampled, and not only on individual preferences. This kind of model is especially relevant for the transition of control in vehicle automation, as it is assumed that drivers in such situations can be overloaded with large volumes of spatially dispersed visual information, and may not be able to process all the information they would need Examples for such overload can be found in Gold et al. (2013) and Blommer et al. (2017), who show that drivers change their decisions about when to resume control from automation, based on the amount of time they have to react before the automated system reaches its limit. Although, it is worth considering that those authors have only considered visual information, so other factors might also have affected the observed results.

Satisficing decision-making models assume that the decision-maker will not seek the most optimal solution for his/her problem, but instead will make the first decision where the outcome satisfies their 
needs or goals in the given situation (Wierzbicki, 1982; Parke et al., 2007). This approach was used in studies by Boer (1999), Boer \& Hoedemaeker (1998), and Goodrich \& Boer (2003), in different scenarios. For example, Boer (1999) demonstrated that drivers tend to have not one specific "ideal carfollowing distance", but rather have a satisficing margin, that floats closer or further to the lead vehicle, where the drivers assume to be safe and close enough to be satisfied and refocus in other demands from the car-following task (such as lateral control of the vehicle), instead of actively re-adjust their following distance to a point they would consider to be ideal.

Most concepts in these models are somewhat interchangeable and can be combined in a descriptive or mechanistic analysis. Their relationship with the field of automation will be discussed in the subsequent sections of this work.

\section{Relationship between human factors challenges and risky decision-making}

Based on the two types of decision-making theory models described above, it is evident that the process of Situation Awareness recovery during the transition control from vehicle automation presents several similarities to the risky decision-making theory, which is discussed in the following sections. Merat et al. (2018) stated that drivers re-enter the cognitive loop of the driving task by acquiring sufficient levels of Situation Awareness. In the same way, Ratcliff \& Smith (2004) claim that whenever an individual is presented with an opportunity to make a decision, they will need to accumulate evidence that will support the choice they eventually make. This direct comparison shows similarities in the applicability of both the concept of evidence accumulation and SA for those theories with the same purpose, which is to understand how humans use the information to react to a given environmental condition and achieve their desired goal. Fig. 2 presents a schematic representation of the proposed relationship between the two theories.

\section{Decision-Making Theory}

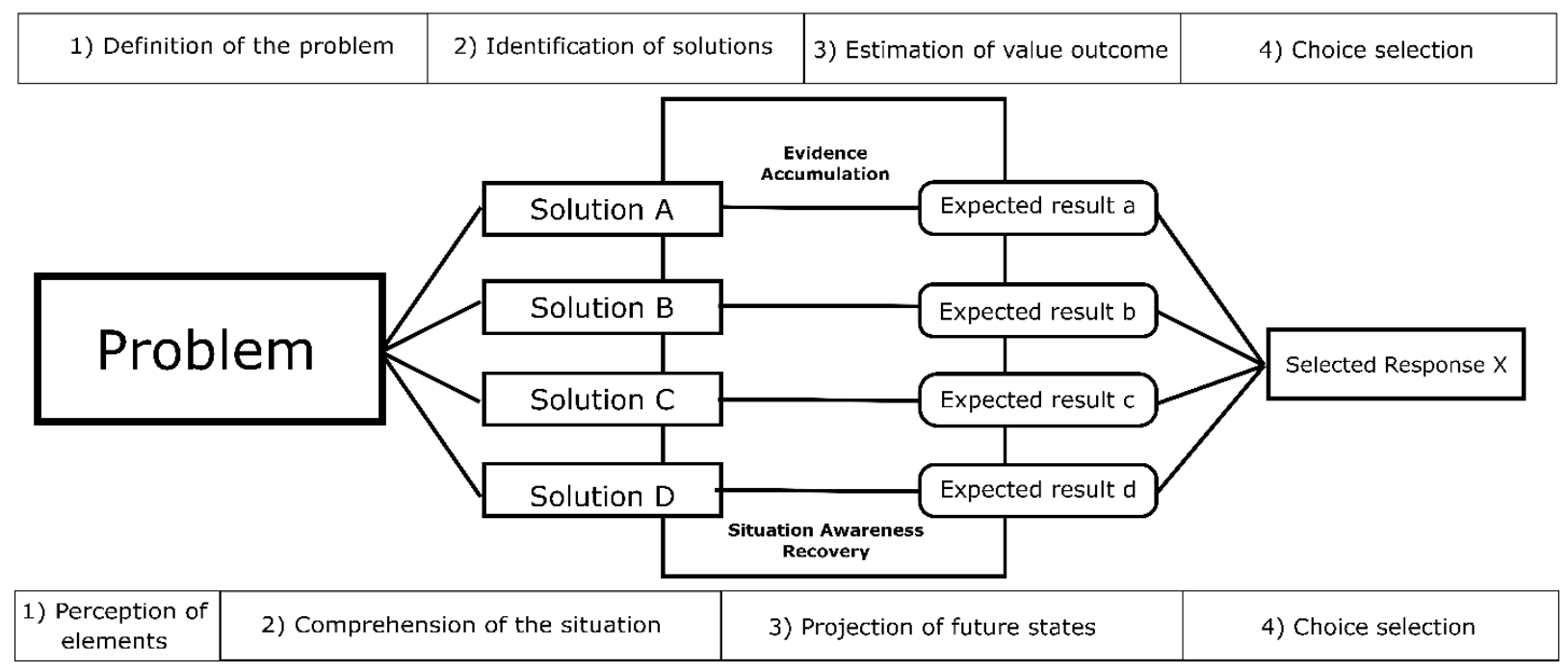

\section{Situation Awareness Theory}

Figure 3. Representation of the relationship between SA and decision-making theory.

As mentioned above, decision-making theory holds that the decision- making process is composed by four steps: 1) define the problem, and understand its characteristics; 2) formulate/generate possible solutions for the given problem; 3 ) estimation of the value of possible outcomes; 4) selection of the outcome with the highest value for the given problem (see Simon, 1959 for a better description). Endsley (1995) divided the SA into levels, in a way that the individual needs to 1) identify the elements 
in the environment, 2) comprehend their meaning, and how it shapes the situation in hand, and 3) orient how those elements can be interacted with, in a way that is possible to predict what can be the outcomes of their potential actions. According to Simon (1957) and Edwards (1954), a decision can only be made if there is a clear notion/definition of the value of each solution to the upcoming problem, and that to achieve this, the decision-maker accumulates evidence that assigns the correct value to a particular option, reducing the decision-maker's level of uncertainty (Shaw, 1982). Observing the same phenomenon through the lenses of the SA theory, we can understand that the comprehension of the problem (in the case of this work, a request to transition control) and their possible solutions as level two SA. The process of assigning value, or expected outcome of possible action in order to make the appropriate decision can be directly linked to the level three situation awareness, or projection of future states. In this framework, it can be assumed that the process of moving from level two to level three SA can be directly compared to the process of accumulation of evidence, which is simply the reduction of uncertainty about the outcomes of a possible action to a given scenario.

The arguments presented in the previous section showed that barriers, called SA challenges (Endsley, 2006), impede an individual's ability to acquire all the sufficient levels of SA they need to make an optimal resumption of control from automation (see Parasuraman \& Riley (1997) for an example of such phenomenon). Analysing the challenges imposed to an individual to resume control from automation through the lens of decision-making theory, a similar problem is reported by Edwards (1954) and Simon (1957) who say that an entirely rational decision is utopic. The authors believe that barriers imposed by the scenario, such as time pressure and bounded rationality, forces the human decisionmaker to deal with uncertainty, by making assumptions about certain conditions about the environment, based on their expectations, and, thus, adopting a risky decision. As examples relating to resumption of control from vehicle automation, Blommer et al. (2017) and Gold et al. (2013) showed that drivers have an increased probability to "just brake", instead of both braking and steering, whenever they had limited time to respond to the scenario. The authors noted that the scenario exceeded drivers' abilities to cope with the situation and to perform the ideal action. These two examples can be translated in the risky decision-making theory as satisficing decision-making actions, where even if it was not perfect, it was the best they could do with the information they had, opting to make a simple reaction to the scenario.

Based on the arguments presented above, we believe that risky decision-making theory is a suitable candidate to model the process of the take-over of control from vehicle automation. The application of decision-making theory can complement the existing studies on the transition, as it can be used to understand the relationship between the information sampled by drivers and their subsequent behaviour. Practically speaking, this approach complements the current studies in the field by providing robust mathematical models that assign causality between evidence accumulation and decision (see Orquin \& Loose, 2013), which are not commonly linked to the situation awareness theory. It is now essential to evaluate how this theory can be applied and implemented to better describe driver behaviour during transitions of control.

\section{Using decision-making models to orient drivers' decision-making}

Sivak (1996) stated that vision is the most important of the five human senses for driving, but yet, it is not suited to dealing with multiple demands at the same time. For this reason, drivers need to prioritise certain visual information over others to perform a transition of control (for more details about this process, see Goodrich \& Boer, 2003).

According to Orquin \& Loose (2013), visual attention and decision-making are tightly coupled, since a driver's risky decision-making is continuously biased by whether or not they attended to relevant visual information available to them. In their literature review, the authors found a co-causal relationship between visual attendance to information and the occurrence of specific choices, in a discrete decision-making scenario. As part of a meta-analysis, the authors analysed several decision-making tasks that used eye-tracking data as a dependent variable. They concluded that an individual's gaze fixation on certain essential information could predict their upcoming choice in a discrete scenario, suggesting that the selective attention of drivers may bias their decision-making. Such an approach may also be applied to analyse drivers' response capabilities in a take-over scenario, once a take-over reaction is nothing more than a selective response to a particular scenario 
condition.

The arguments above support the possibility of modelling the relationship between different gaze allocation strategies and the probability of yielding specific responses to the take-over control scenario (based on the studies reported by Orquin \& Loose, 2013). This approach would inform system designers about which information should be scanned with higher priority, to yield a higher probability of safe and timely responses to different take-over scenarios. This information could be used to create HMIs that guide drivers towards making decisions that result in safe outcomes. For example, indicating where drivers should focus their attention on a successful transition of control could help avoid an impending collision, as suggested by Louw et al. (2017).

\section{Formulation of a take-over model}

In previous sections, it was discussed theoretically how evidence accumulation models can be applied to understand and predict drivers' take-over behaviour. Evidence from previous literature suggests that inputs from eye movements to the models can create a robust way to understand drivers decision-making process. This section of the paper describes the process of formulation of a mathematical model that can be applied for data fitting suited for the process of transition of control in vehicle automation, based on the elements discussed above.

According to Wagenmakers et al. (2008), evidence accumulation models use real data from experiments to estimate how the process of information acquisition for every individual participant leads to their decision. It receives as the input variable response times ( $t$ ) and choice selection (p) of every individual, and based on the individual differences across data samples, they can draw assumptions based on probability distributions of how humans make decisions. According to the authors, and many others in the field (see Ratcliff et al., 2004 for a more descriptive explanation about evidence accumulation models), the main estimated parameters in this kind of model are:

1. Mean drift rate (v), or how quickly evidence is accumulated towards the decision.

2. Boundary limit for the decision (a), or how much evidence needs to be accumulated for a decision to be made.

3. Previous knowledge or information that may speed up the decision process (z), also known as bias.

4. Inter-participant variability (s), which assumes that different people have faster/slower processes of evidence accumulation.

Fig. 4 shows how all those variables are fit together in a graphical representation of the model and how the parameters are estimated. It is now necessary to understand how the context of the transition of control and situation awareness acquisition can be translated in this kind of model, and also how data related to visual attention allocation can be used to generate more accurate descriptions of drivers' decision-making behaviour.

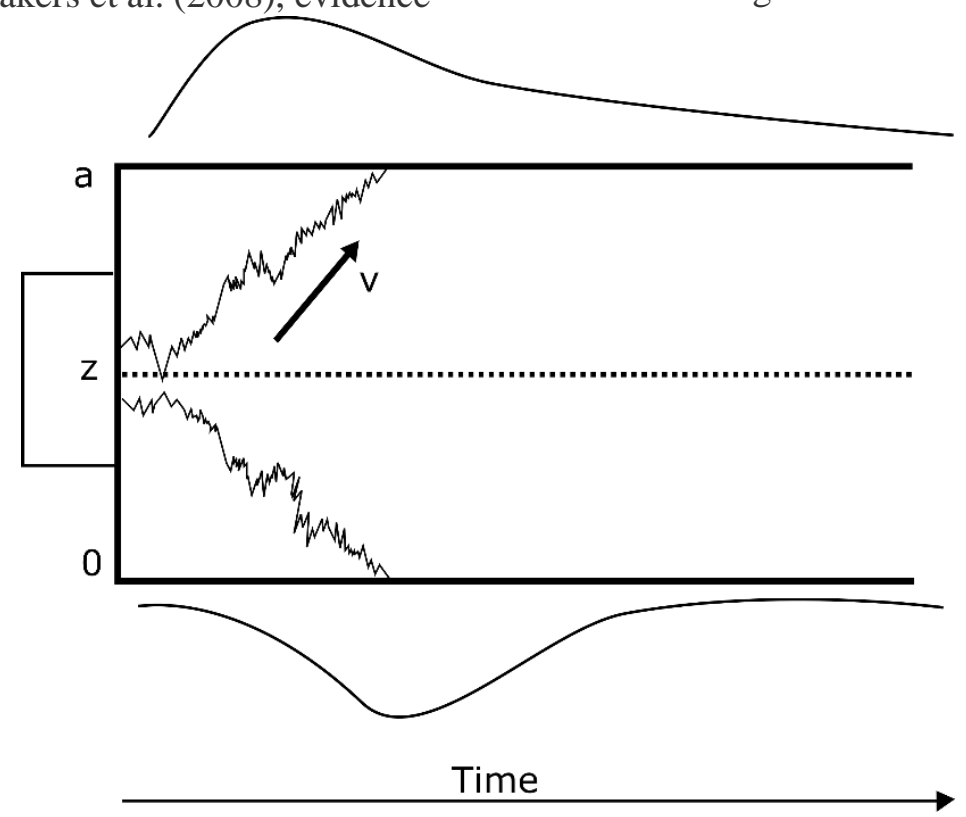

Figure 4. Graphical representation of an evidence accumulation model. Source: Ratcliff et al. (2004). 
As already said before, the process of situation awareness acquisition can be directly translated as the process of evidence accumulation, in a way that drivers have as their primary goal to safely recover manual control of a vehicle, and will sample information about the multiple options they have to do so, until they reach a point that they are confident enough about one specific option and engage in the task execution. As the situation awareness acquisition process is mainly defined as a visual task (Gartenberg et al., 2014), and the process of transition of control is mainly constrained by bounded rationality (for examples, see Endsley, 2006), it is possible to assume that different gaze sample patterns would inherently bias the accumulation process, leading to both different response times, and probability of certain response to happen. With this argument in mind, it is then necessary to insert in the model a variable related to gaze allocation over time, which controls how much evidence can be accumulated over time, based in where the drivers are looking (drift rate).

Since this paper describes only a proof of concept for the theory presented above, we opted to develop an adapted version of a linear ballistic accumulator model (LBA; Brown \& Heathcote, 2008). This technique was chosen due to its simplified math (easy to explain) and low computational power requirements for its implementation. Future studies might want to consider more robust models, which also includes other explanatory variables (eg. driftdiffusion models). The LBA model is an evidencebased decision-making model, which assumes that the process of evidence accumulation related to one possible choice is independent of the other, in a way that two possible decision choices are calculated separatelly, as if they were diferent scenarios. The second assumption of the model is that there is no internal variability or noise in the process of evidence accumulation. For every sample, it generates a linear function between evidence and time. The differences in the response profiles can be only observed by across-participants differences (Dokin et al., 2009).

The flowchart below (Fig. 5) is the conceptual representation of the proposed model, where drivers, after receiving a take-over request, would gather visual information, in a goal-directed top-down approach, to accumulate evidence about a possible solution to the task. This evidence would be combined with their previous information about the situation (current SA levels) and their personal bias and would accumulate until it reaches a threshold of satisficing levels, triggering the execution of an action. In this scenario, different sources of visual information would lead to a different drift rate, causing variability in drivers' take-over time. In this process, every possible decision is calculated and modelled separately.

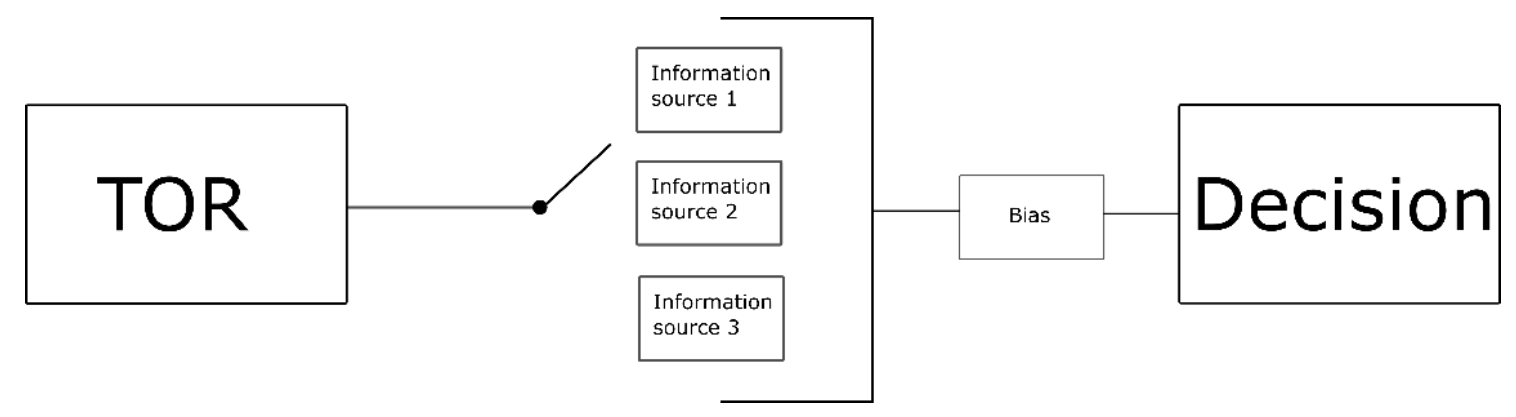

Figure 5. Graphical representation of an evidence accumulation model. Source: Ratcliff et al. (2004).

In terms of calculation, the purposed formula assumes that take-over time (tot) is the sum of the total time drivers spent gazing towards the $n$ different sources (i) of information. Also, the process of accumulation of evidence is defined as the sum of the time drivers spent looking at each information source ( $\left.t \_i\right)$, times a constant, which indicates the drift rate, related to each specific information source (v_i). See below the two equations that define the base formula of the model.

$$
\begin{aligned}
& \text { 1) } T o T=\sum_{i=1}^{n} t_{i} \\
& \text { 2) } a=z+\left(\sum_{i=1}^{n} t_{i} * v_{i}\right) * s
\end{aligned}
$$

Equation 1. Formulation for the take-over decisionmaking model. ToT is the take-over time; $t$ is the time drivers spent gazing towards each information source $\mathrm{i} ; \mathrm{z}$ is drivers' previous knowledge about the situation and personal bias; $v$ is the drift rate for every information source; $a$ is the estimated threshold for the decision- 
making, and $\mathrm{s}$ is the ratio for individual differences.

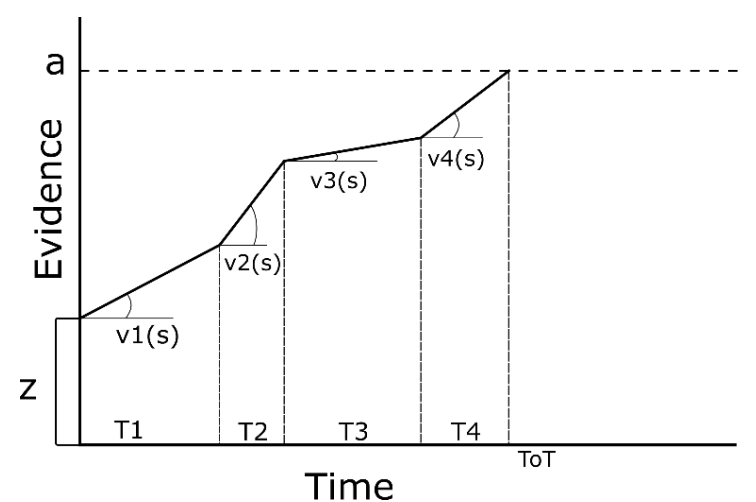

Figure 6. Graphical representation of the output from the proposed model.

With this approach, it is possible to estimate how valuable certain information source $i$ is for the decision-making process, assuming that it would affect drivers' decisions in the same way. As for the assumptions of the model, 1) it assumes that the process of information acquisition is constant and linear, and does not account for information saturation of one source, nor to noise on the process of information acquisition; 2) it assumes that every option is computed individually, and not in a conflicting way, as a drift-diffusion model would (Ratcliff et al., 2004); 3) it assumes that drivers are in time pressure, in a way that they would perform the decided action as soon as they decided what to do, as mind-wandering and non-decision-making related data would add noise to the model.

\section{Conclusion}

The primary aim of this paper was to assess the feasibility of applying risky decision-making theory models to understand drivers' take-over behaviour during transitions of control from vehicle automation. A secondary aim was to explain how decision-making models could be implemented by system designers as a tool to understand human behaviour and create products that better suit driver needs.

The initial sections point out similarities between the theories on SA and risky decision-making, which makes them comparable and applicable for similar purposes. The main points of proximity between the two theories include the concepts of evidence accumulation and level three situation awareness, respectively, to account for how humans make a decision in a given scenario. We also proposed that models that correlate vision and decision-making modality as a causal factor could be used to identify which information, once sampled, can increase the probability for drivers to perform a supposed "optimal response". In conclusion, we propose that decision-making models, based on evidence accumulation, can be used in HMI design, to enhance drivers' acquisition of certain essential information and, thereby, optimise their take-over performance. For example, if we know how drivers sample visual information before an optimal response, and we use this knowledge to design HMIs to reproduce this behaviour in other drivers in similar situations, then we may increase the probability that they respond similarly.

As for limitations and future directions, this work is chiefly a theoretical consideration and lacks sufficient evidence to defend the real value of the application of decision-making models in the design process for human-centric vehicle automation systems. Empirical studies are required to evaluate how well decision-making models can predict drivers' take-over modality, and whether, if certain information is highlighted in the system design, drivers' performance in take-over scenarios can be enhanced.

\section{References}

\section{BAINBRIDGE, L. Ironies of Automation.}

Automatica, v. 19, n. 6, p. 775-779, 1983.

BELL, DE e RAIFFA, H e TVERSKY, A. Decision making: Descriptive, normative, and prescriptive interactions. 1988. Disponível em:

$<$ https://books.google.com/books?hl=pt-

BR\&lr=\&id=R2dleyi_iTMC\&oi=fnd\&pg=PR9\&dq

$=$ Bell+et+al.,+1988+decision \&ots=VKjKvg4Jjr\&sig =RS_rzA0yF_bXVfz-5_9mwusjjCU>. Acesso em: 15 set 2019.

BLOMMER, Mike e colab. Driver brake vs. steer response to sudden forward collision scenario in manual and automated driving modes.

Transportation Research Part F: Traffic Psychology and Behaviour, v. 45, p. 93-101, 1 Fev 2017.

Disponível em:

<https://www.sciencedirect.com/science/article/abs/ pii/S1369847816305587>. Acesso em: 15 set 2019.

BOER, Erwin R. Car following from the driver's perspective. Transportation Research Part F: Traffic Psychology and Behaviour, v. 2, n. 4, p. 201-206, 1 Dez 1999. Disponível em:

<http://www.sciencedirect.com/science/article/pii/S1 369847800000073>. Acesso em: 10 nov 2017. 
PUC-Rio Pontifícia Universidade Católica do Rio de Janeiro Departamento de Artes \& Design | PPGDesign

LEUI | Laboratório de Ergodesign e Usabilidade de Interfaces

BOER, Ewin R e HOEDEMAEKER, Marika.

Modeling driver behavior with different degrees of automation: a hierarchical décision framework of interacting mental models. 1998. Disponível

em:

<https://repository.tudelft.nl/islandora/object/uuid:1 0f1d366-768d-4c0c-acae-

11f6cb597727/datastream/OBJ>. Acesso em: 9 nov 2017.

BROWN, S. D., \& HEATHCOTE, A. The simplest complete model of choice response time: Linear ballistic accumulation. Cognitive psychology, 57(3), 153-178. 2008.

CARSTEN, Oliver e colab. Control Task Substitution in Semiautomated Driving. Human Factors: The Journal of the Human Factors and Ergonomics Society, v. 54, n. 5, p. 747-761, 17 Out 2012. Disponível em:

<http://journals.sagepub.com/doi/10.1177/00187208 12460246>. Acesso em: 9 nov 2017.

CRUNDALL, D. e UNDERWOOD, G. e CHAPMAN, $P$. Driving experience and the functional field of view. Perception, v. 28, n. 9, p. 1075-1087, 1999.DAMBOCK, D. e colab. Requirements for cooperative vehicle guidance. Out 2013, [S.1.]: IEEE, Out 2013. p. 1656-1661.

Disponível em:

<http://ieeexplore.ieee.org/document/6728467/>. Acesso em: 9 nov 2017.

DONKIN, C., BROWN, S. D., \& HEATHCOTE, A. The overconstraint of response time models: Rethinking the scaling problem. Psychonomic Bulletin \& Review, 16(6), 1129-1135. 2009.

EDWARDS, Ward. The theory of decision making. Psychological Bulletin, v. 51, n. 4, p. 380417, 1954. Disponível em:

$<$ http://doi.apa.org/getdoi.cfm?doi=10.1037/h00538 70>. Acesso em: 21 jul 2019.

ENDSLEY, Mica R. Situation Awareness. Handbook of Human Factors and Ergonomics. Hoboken, NJ, USA: John Wiley \& Sons, Inc., 2006. p. 528-542. Disponível em: <http://doi.wiley.com/10.1002/0470048204.ch20>. Acesso em: 10 nov 2017.

ENDSLEY, Mica R. Design and Evaluation for Situation Awareness Enhancement. Proceedings of the Human Factors Society Annual Meeting, v. 32, n. 2, p. 97-101, 6 Out 1988. Disponível em: <http://journals.sagepub.com/doi/10.1177/15419312
8803200221>. Acesso em: 15 set 2019.

ENDSLEY, Mica R. e KIRIS, Esin O. The Out-ofthe-Loop Performance Problem and Level of Control in Automation. Human Factors: The Journal of the Human Factors and Ergonomics Society, v. 37, n. 2, p. 381-394, 23 Jun 1995. Disponível em:

<http://journals.sagepub.com/doi/10.1518/00187209 5779064555>. Acesso em: 10 nov 2017.

FIEDLER, Susann e GLÖCKNER, Andreas. The Dynamics of Decision Making in Risky Choice: An Eye-Tracking Analysis. Frontiers in Psychology, v. 3, p. 335, 1 Out 2012. Disponível em:

<http://journal.frontiersin.org/article/10.3389/fpsyg. 2012.00335/abstract>. Acesso em: 15 set 2019.

GARTENBERG, Daniel e colab. Situation

Awareness Recovery. Human Factors: The Journal of the Human Factors and Ergonomics Society, v. 56, n. 4, p. 710-727, 7 Jun 2014. Disponível em: <http://journals.sagepub.com/doi/10.1177/00187208 13506223>. Acesso em: 15 set 2019.

GIPPS, P. G. A model for the structure of lanechanging decisions. Transportation Research Part B: Methodological, v. 20, n. 5, p. 403-414, 1986.

GKIKAS, Nikolaos. Automotive ergonomics : driver-vehicle interaction. [S.1.]: CRC Press, 2013.

GOLD, Christian e colab. "Take over!" How long does it take to get the driver back into the loop? Proceedings of the Human Factors and Ergonomics Society Annual Meeting, v. 57, n. 1, p. 1938-1942, 30 Set 2013. Disponível em: <http://journals.sagepub.com/doi/10.1177/15419312 13571433>. Acesso em: 9 nov 2017.

GOLD, Christian e HAPPEE, Riender e BENGLER, Klaus. Modeling take-over performance in level 3 conditionally automated vehicles. Accident Analysis \& Prevention, v. 116, p. 3-13, 1 Jul 2018. Disponível em:

<https://www.sciencedirect.com/science/article/abs/ pii/S0001457517303962>. Acesso em: 21 jul 2019.

GOODRICH, M.A. e BOER, E.R. Multiple mental models, automation strategies, and intelligent vehicle systems. n. May 2014, p. 859-864, 2003.

LOUW, Tyron Linton. The Human Factors Of Transitions In Highly Automated Driving. 2017. University of Leeds, 2017. 
PUC-Rio Pontifícia Universidade Católica do Rio de Janeiro Departamento de Artes \& Design | PPGDesign

LEUI | Laboratório de Ergodesign e Usabilidade de Interfaces

LOUW, Tyron e colab. Engaging in NDRTs affects drivers' responses and glance patterns after silent automation failures. Transportation Research Part F: Traffic Psychology and Behaviour, v. 62, p. 870882, 1 Abr 2019. Disponível em:

<https://www.sciencedirect.com/science/article/abs/ pii/S1369847818307952>. Acesso em: 15 set 2019.

LOUW, Tyron e colab. Were they in the loop during automated driving? Links between visual attention and crash potential. Injury prevention : journal of the International Society for Child and Adolescent Injury Prevention, v. 23, n. 4, p. 281286, 21 Ago 2016. Disponível em:

<http://www.ncbi.nlm.nih.gov/pubmed/27655754>. Acesso em: 9 nov 2017.

LOUW, Tyron e colab. Coming back into the loop: Drivers' perceptual-motor performance in critical events after automated driving. Accident Analysis \& Prevention, v. 108, p. 9-18, 1 Nov 2017. Disponível em:

<http://www.sciencedirect.com/science/article/pii/S0 $001457517302907>$. Acesso em: 10 nov 2017.

LOUW, Tyron e MERAT, Natasha. Are you in the loop? Using gaze dispersion to understand driver visual attention during vehicle automation.

Transportation Research Part C: Emerging

Technologies, v. 76, p. 35-50, 1 Mar 2017.

Disponível em:

<http://www.sciencedirect.com/science/article/pii/S0 968090X17300013>. Acesso em: 9 nov 2017.

MADIGAN, Ruth e LOUW, Tyron Linton e MERAT, Natasha. Effects of varying levels of vehicle automation on drivers lane changing decisions and performance. Transportation Research Part F: Traffic Psychology and Behaviour, 2017.

MARCH, James G. Bounded Rationality, Ambiguity, and the Engineering of Choice. The Bell Journal of Economics, v. 9, n. 2, p. 587, 1978. Disponível em:

<https://www.jstor.org/stable/3003600?origin=cross ref>. Acesso em: 15 set 2019.

MARKKULA, Gustav e colab. Models of Human Decision-Making as Tools for Estimating and Optimizing Impacts of Vehicle Automation. Transportation Research Record: Journal of the Transportation Research Board, v. 2672, n. 37, p. 153-163, 25 Dez 2018. Disponível em: <http://journals.sagepub.com/doi/10.1177/03611981
18792131>. Acesso em: 15 set 2019.

MERAT, Natasha e colab. Transition to manual: Driver behaviour when resuming control from a highly automated vehicle. Transportation Research Part F: Traffic Psychology and Behaviour, v. 27, p. 274-282, 1 Nov 2014. Disponível em:

<http://www.sciencedirect.com/science/article/pii/S1 369847814001284>. Acesso em: 9 nov 2017.

MERAT, Natasha e colab. The "Out-of-the-Loop" concept in automated driving: proposed definition, measures and implications. Cognition, Technology and Work, v. 21, n. 1, p. 87-98, 2018. Disponível em: <http://dx.doi.org/10.1007/s10111018-0525-8>.

MILL, John Stuart. On Liberty. A Selection of his Works. London: Macmillan Education UK, 1966. p. 1-147. Disponível em:

<http://link.springer.com/10.1007/978-1-349-817801_1>. Acesso em: 15 set 2019. NASH, J F e JR.

Equilibrium Points in N-Person Games. Proceedings of the National Academy of Sciences of the United States of America, v. 36, n. 1, p. 48-9, Jan 1950.

Disponível em:

<http://www.ncbi.nlm.nih.gov/pubmed/16588946>. Acesso em: 21 jul 2019.

NATIONAL HIGHWAY TRAFFIC SAFETY ADMINISTRATION. Federal Automated Vehicles Policy. 2016.

NIELSEN, Jakob. Mental Models, 2010. Disponível em <

https://www.nngroup.com/articles/mental-models/>. Acesso em: 21 jul 2019.

NIESSER, Ulric. Review: Cognition and Reality:

Principles and Implications of Cognitive

Psychology. Perception, v. 6, n. 5, p. 605-610,

1977. Disponível em:

<https://psycnet.apa.org/record/2003-00066-000>. Acesso em: 15 set 2019.

OHN-BAR, Eshed e TRIVEDI, Mohan Manubhai.

Looking at Humans in the Age of Self-Driving and Highly Automated Vehicles. IEEE

Transactions on Intelligent Vehicles, v. 1, n. 1, p. 90-104, Mar 2016. Disponível em:

<http://ieeexplore.ieee.org/document/7501845/>. Acesso em: 15 set 2019.

ORQUIN, Jacob L. e MUELLER LOOSE, Simone. Attention and choice: A review on eye movements in decision making. Acta 
PUC-Rio Pontifícia Universidade Católica do Rio de Janeiro Departamento de Artes \& Design | PPGDesign

LEUI | Laboratório de Ergodesign e Usabilidade de Interfaces

Psychologica, v. 144, n. 1, p. 190-206, 1 Set 2013. Disponível em:

<https://www.sciencedirect.com/science/article/pii/S 0001691813001364>. Acesso em: 21 jul 2019.

PARASURAMAN, Raja e RILEY, Victor. Humans and Automation: Use, Misuse, Disuse, Abuse. Human Factors: The Journal of the Human Factors and Ergonomics Society, v. 39, n. 2, p. 230-253, 23 Jun 1998. Disponível em:

<http://journals.sagepub.com/doi/10.1518/00187209 7778543886>. Acesso em: 9 nov 2017.

PARKER, Andrew M., WÄNDI Bruine de Bruin, And BARUCH Fischhoff. Maximizers versus satisficers: Decision-making styles, competence, and outcomes. sjdm.cybermango.org, 2007.

Disponível em:

<http://sjdm.cybermango.org/journal/jdm7830.pdf > . Acesso em: 15 set 2019.

RATCLIFF, R e SMITH, P.L. A comparison of sequential sampling models for two-choice reaction time. psycnet.apa.org, 2004. Disponível em: <https://psycnet.apa.org/record/2004-12248003>. Acesso em: 15 set 2019.SAE.

Summary of SAE International's Levels of Driving Automation for On-Road Vehicles. Disponível em:

<https://www.sae.org/misc/pdfs/automated_driving. pdf>. Acesso em: 9 nov 2017.

SHAW, Marilyn L. Attending to multiple sources of information: $I$. The integration of information in decision making. Cognitive Psychology, v. 14, n. 3, p. 353-409, 1982.

SIMON, Herbert A. Theories of bounded rationality. Decision and organization. CBR a. R. Radner. Amsterdam, NorthHolland, 1972.

SIMON, Herbert A. Theories of decision-making in economics and behavioral science. The American economic review, v. 49., n. 3, p. 253-283, 1959.

SIMON, Herbert A. Rational decision making in business organizations. JSTOR, 1979. Disponível em:

<https://www.jstor.org/stable/1808698?casa_token= 23x1R16dBJsAAAAA:p6KBIkBL-

8xJWORKJ1v2c9J1Qsy_Mpd26QVZVkm7K5z9b5 ORMeY1PVfTK3LCB6BSQ3eYNE4JRYsIxuik4v GdkZOMV4EIh36z8xt-1KFyIWmhniOy6IR9>.

Acesso em: 15 set 2019.
SIVAK, Michael. The Information That Drivers Use: Is it Indeed 90\% Visual? Perception, v. 25, n. 9, p. 1081-1089, 25 Set 1996. Disponível em: <http://journals.sagepub.com/doi/10.1068/p251081> . Acesso em: 15 set 2019.

VICTOR, Trent W. e colab. Automation

Expectation Mismatch: Incorrect Prediction Despite Eyes on Threat and Hands on Wheel. Human Factors: The Journal of the Human Factors and Ergonomics Society, v. 60, n. 8, p. 1095-1116, 10 Dez 2018. Disponível em:

<http://journals.sagepub.com/doi/10.1177/00187208 18788164>. Acesso em: 21 jul 2019.

WAGENMAKERS, E. J., VAN DER MAAS, H. L., Dolan, C. V., \& Grasman, R. P. EZ does it!

Extensions of the EZ-diffusion model.

Psychonomic Bulletin \& Review, 15(6), 1229-1235. 2008.

WICKENS, Christopher D. Situation Awareness: Review of Mica Endsley's 1995 Articles on Situation Awareness Theory and Measurement. Human Factors: The Journal of the Human Factors and Ergonomics Society, v. 50, n. 3, p. 397-403, 1 Jun 2008. Disponível em:

<http://journals.sagepub.com/doi/10.1518/00187200 8X288420>. Acesso em: 15 set 2019.

WIERZBICKI, Andrzej P. A mathematical basis for satisficing decision making. Mathematical Modelling, v. 3, n. 5, p. 391-405, 1 Jan 1982.

Disponível em:

<https://www.sciencedirect.com/science/article/pii/0 270025582900380>. Acesso em: 15 set 2019.

YOUNG, Mark. Ergonomics Issues with Advanced Driver Assistance Systems (ADAS). Automotive Ergonomics. [S.1.]: CRC Press, 2012. p. 55-76.

Disponível em:

<http://www.crenetbase.com/doi/10.1201/b130176>. Acesso em: 22 jan 2017.

ZEEB, Kathrin e BUCHNER, Axel e SCHRAUF, Michael. What determines the take-over time? An integrated model approach of driver take-over after automated driving. Accident Analysis \& Prevention, v. 78, p. 212-221, Maio 2015.

Disponível em:

<http://www.ncbi.nlm.nih.gov/pubmed/25794922>. Acesso em: 23 jan 2017.

ZEEB, Kathrin e BUCHNER, Axel e SCHRAUF, Michael. Is take-over time all that matters? the impact of visual-cognitive load on driver take- 
over quality after conditionally automated

driving. Accident Analysis and Prevention, v. 92, p.

230-239, 2016. Disponível em:

<http://dx.doi.org/10.1016/j.aap.2016.04.002> 